BACKGROUND: In smoking COPD patients the bronchoalveolar lavage (BAL) fluid contains high numbers of inflammatory cells. These cells might produce arachidonic acid (AA) metabolites, which contribute to inflammation and an increased bronchomotor tone.

Aims: To investigate levels of AA metabolites in BAL fluid, before and after inhaled glucocorticoid therapy: fluticasone propionate (FP) $1 \mathrm{mg}$ per day, or placebo.

Methods: A double-blind placebo controlled trial lasting six months. COPD patients were selected by clinical criteria and the presence of bronchial hyperresponsiveness (BHR). Lung function was recorded and in BAL fluid we counted cell numbers and measured $\mathbf{L T B}_{4}, \mathbf{L T C}_{4} / \mathrm{D}_{4} / \mathrm{E}_{4}, \mathbf{P G E}_{2}, 6 \mathrm{KPGF}_{1} \alpha, \mathbf{P G F}_{2} \alpha$ and $T \mathrm{XB}_{2}$. A control group consisted of asymptomatic smokers $(n=6)$.

Results: Paired data were obtained from 9 FP treated and 11 placebo patients. BAL cells were almost exclusively alveolar macrophages. In patients and controls both cellularity and levels of $\mathrm{AA}$ metabolites were equal. Cell numbers did not change after treatment. Statistically significant decreases after FP therapy were noticed for PGE $2(30 \%), 6 \mathbf{k P G F}_{1} \alpha(41 \%)$ and $\mathrm{PGF}_{2} \alpha(54 \%)$.

Conclusions: In COPD, the capability of inflammatory cells to produce certain AA metabolites was decreased after inhaled FP treatment. This result is discussed in its relation to clinical effects, the influence of smoking, and the results of an earlier, similar study in asthma patients.

\section{Effects of fluticasone propionate inhalation on levels of arachidonic acid metabolites in patients with chronic obstructive pulmonary disease}

\author{
Gert T. Verhoeven ${ }^{1, C A}$, Ingrid M. Garrelds ${ }^{2}$, \\ Henk C. Hoogsteden ${ }^{1}$ and Freek J. Zijlstra ${ }^{3}$
}

\begin{abstract}
${ }^{1}$ Department of Pulmonary and Intensive Care Medicine, ${ }^{2}$ Department of Pharmacology and ${ }^{3}$ Department of Anesthesiology, University Hospital Dijkzigt and Erasmus University, EMCR, Rotterdam, The Netherlands.
\end{abstract}

\author{
${ }^{\mathrm{CA}}$ Corresponding Author \\ Tel: +31 104634862 \\ Fax: +31 104634856 \\ E-mail: Verhoeven@lond.azr.nl
}

\section{Introduction}

Leukotrienes (LTs) and prostaglandins (PGs) are mediators of inflammation that have been investigated almost exclusively in asthma, but not in COPD. These metabolites of arachidonic acid (AA) are products of several inflammatory cells and part of the mechanisms leading to bronchoconstriction and increased bronchomotor tone. In chronic obstructive pulmonary disease (COPD) airway narrowing is caused by several mechanisms, including mechanical factors (loss of elasticity of the lung parenchyma), increased thickness of the walls of the conducting airways, increased bronchomotor tone and intraluminal secretions. ${ }^{1,2}$ Increased numbers of alveolar macrophages, neutrophilic granulocytes and CD8 positive cells constitute the main burden of the cellular infiltrate in the airway walls and alveoli. Their secretory products cause multiple effects, for instance cell influx and cell activation, but also an increase of the contractile status of the smooth muscles in the small bronchi. Among these cell products, AA metabolites are known for their potent bronchoconstrictor activity.
Therefore, we hypothesized that AA metabolites could also be detected in COPD and anti-inflammatory treatment could influence their levels. Samples of BAL supernatant were collected at the start and after six months of a double-blind trial comparing the effect of fluticasone propionate (FP) with placebo, in smoking COPD patients. We decided to study a subgroup of COPD patients, particularly those with bronchial hyperresponsiveness (BHR), because these patients are subject to an even more accelerated decline of their $\mathrm{FEV}_{1},{ }^{3,4}$ This could indicate a severe inflammatory infiltrate, increased levels of AA metabolites and potentially an effect of an inhaled glucocorticoid. Smokers without symptoms and with normal lung function served as controls.

\section{Material and methods}

Patients

COPD patients were selected according to generally accepted clinical and functional criteria. ${ }^{5}$ Inclusion criteria were: age between 40 and 70 years, current smoker, $\mathrm{FEV}_{1} / \mathrm{iVC}$ ratio $\leq 70 \%$ of predicted normal 
values (pred), reversibility of $\mathrm{FEV}_{1}<10 \%$ pred after $750 \mu \mathrm{g}$ terbutaline, non-specific BHR - defined by a $\mathrm{PC}_{20}$ histamine $\leq 8 \mathrm{mg} / \mathrm{ml}$ - and negative skin tests for standard inhaled allergens. Reference values were obtained from ECCS standards. ${ }^{6}$ The main exclusion criteria were a history of asthma and recent respiratory tract infection. Any anti-inflammatory therapy, including corticosteroids, non-steroidal anti-inflammatory drugs and theophyllines, was discontinued. Potential candidates for this study were informed about the negative effects of smoking, and we offered them the opportunity to participate in a smokingcessation program. The Hospital's Medical Ethics Committee approved the study. Written informed consent was obtained from all participants.

\section{Design of the intervention study}

We performed a double-blind, placebo-controlled study that lasted for six months. Patients were randomly assigned to either twice-daily $500 \mu \mathrm{g}$ FP or placebo, which were delivered via a similar diskhaler. The start of treatment was immediately after the first bronchoscopy. Bronchoscopy was repeated at the end of the study. Follow-up visits were at intervals of four weeks.

\section{Bronchoscopy}

The procedure was carried out according to international guidelines. ${ }^{7}$ For local anaesthesia we used lidocaine spray and aerosolised oxybuprocaine. The bronchoscope (Olympus BF 1T10) was advanced into the lateral segment of the middle lobe, in wedge position. Lavage was performed successively with $1 \times 40 \mathrm{ml}$ and $4 \times 50 \mathrm{ml}$ sterile phosphate-buffered saline (PBS) solution (Organon Teknika, Boxtel, The Netherlands) at body temperature $\left(37^{\circ} \mathrm{C}\right)$ and $\mathrm{pH} 7.4$. Aliquots were aspirated in two siliconized specimen traps, one for the first 'bronchoalveolar fraction' after $40 \mathrm{ml}$ PBS and the second 'alveolar fraction' for the recovery of the $4 \times 50 \mathrm{ml}$ PBS. The lavage fluid was transported to the laboratory on ice and processed immediately. The recovery of the first, bronchoalveolar fraction appeared to be low and insufficient for performing the desired experiments.

\section{Processing of BAL fluid}

After measurement of volume, the BAL fluid was filtered through sterile nylon gauzes and centrifuged at $400 \times g$ at $4^{\circ} \mathrm{C}$ for $5 \mathrm{~min}$. The cell pellet was washed in PBS supplemented with $0.5 \%$ bovine serum albumin. The total cell number in the BAL cell suspension was counted in a Coulter Counter Model ZM (Coulter Electronics, Hialeah, FL, USA) and viability was assessed by cellular exclusion of trypan blue. With FACScan flow-cytometry (Becton Dickinson, San Jose,
CA, USA) we analyzed $\mathrm{CD}^{+}$T-cells. Immunocytochemistry of cytospins was carried out with the APAAP (alkaline phosphatase anti-alkaline phosphatase) method and the monoclonal antibodies CD68 (alveolar macrophages), CD15 (VIM-D5, neutrophils) and BMK-13 (eosinophils). Two independent observers counted at least 300 cells in each cytospin.

\section{Determination of concentrations of AA metabolites}

In an earlier publication this has been described in more detail. ${ }^{8}$ In summary, immediately after the BAL procedure, $20 \mathrm{ml}$ of supernatant was processed on C18 SepPak cartridges (Millipore, Bedford, MA), eluated with $2.5 \mathrm{ml}$ methanol and stored at $-80^{\circ} \mathrm{C}$ until analysis. Samples of $200 \mu 1$ BAL eluted fluid were pipetted into polypropylene tubes and dried with a Savant sample concentrator. After dissolving in $300 \mu 1$ assay buffer, levels of thromboxane $\mathrm{B}_{2}\left(\mathrm{TxB}_{2}\right)$ and $\mathrm{LTB}_{4}$ were determined by means of a $\left[{ }^{3} \mathrm{H}\right]$ RIA with antisera from Advanced Magnetics Inc. (Cambridge, MA) and $\left[{ }^{3} \mathrm{H}\right]$ labelled compounds from Amersham International (Buckinghamshire, UK). Levels of $\mathrm{PGE}_{2}$ and $\mathrm{PGF}_{2} \alpha$ were determined with commercially available $\left[{ }^{3} \mathrm{H}\right]$ kits (Amersham, UK) and $6 \mathrm{kPGF}_{1} \alpha$ with a $\left[{ }^{125} \mathrm{I}\right]$ RIA kit (Du Pont de Nemours, Dreieich, Germany), according to the manufacturer's instructions. $\mathrm{LTC}_{4} / \mathrm{D}_{4} / \mathrm{E}_{4}$ was measured at room temperature in a microtitre enzyme immunoassay according to protocol (Biotrak, Amersham, UK). The cross reactivity of the $\mathrm{LTC}_{4}$ antibody with $\mathrm{LTD}_{4}$ was $100 \%$ and with $\mathrm{LTE}_{4}, 30 \%$. Cross reactivities for the other assays to related compounds were negligible or less than $2 \%$ at $\mathrm{B} / \mathrm{Bo} 50 \%$.

\section{Statistics}

Data are expressed as mean \pm SD or as median (range), depending on distribution of data. Differences between patient groups were tested with either the (unpaired) Student $t$-test or the Mann-Whitney test, depending upon distribution of data. Pre- and postintervention data were tested for significant difference with the paired $t$-test or the Wilcoxon signed rank test. Statistical significance was considered at $p<0.05$.

\section{Results}

From the initial 23 participants in the intervention study, paired results were obtained from $9 \mathrm{FP}$ patients and from 12 patients with placebo. The reason for missing paired data were insufficient recovery of either BAL fluid or BAL cells. Characteristics of patients $(n=21)$ and controls are listed in Table 1 . Baseline characteristics of the FP and the placebo group did not differ significantly. The COPD patients 
Table 1. Patient characteristics

\begin{tabular}{lccc}
\hline & Fluticasone propionate & Placebo & Asymptomatic smokers \\
\hline$N$ & 9 & 12 & 6 \\
Age, years & $54 \pm 8$ & $56 \pm 8$ & $44 \pm 9$ \\
Cigarettes/day & $15 \pm 8$ & $16 \pm 7$ & $21 \pm 10$ \\
Pack years & $25 \pm 12$ & $26 \pm 10$ & $23 \pm 12$ \\
FEV $\%$ pred & $66 \pm 13$ & $61 \pm 12$ & $93 \pm 11$ \\
FEV ${ }_{1}$ reversibility, $\%$ & $5.3 \pm 3.7$ & $5.6 \pm 2.7$ & $4.0 \pm 3.0$ \\
PC $_{20}$ histamine, $\mathrm{mg} / \mathrm{ml}$ & $2.6 \pm 2.4$ & $0.8 \pm 0.6$ & $>8$ \\
\hline
\end{tabular}

Mean \pm SD

had on average moderately severe obstructive airways disease and severe $\mathrm{BHR}$. $\mathrm{FEV}_{1}$ \%pred and $\mathrm{PC}_{20}$ were within the range of normal values in the group of asymptomatic smokers, due to selection.

Compliance with study medication was high. The percentage of returned used blisters (which contained FP or placebo) was 92.5 in the FP and 92.7 in the placebo group. In the placebo group, mean $\mathrm{FEV}_{1}$ declined from $61.4 \%$ pred at the start of the trial to $52.0 \%$ pred after 6 months. On the other hand, in the FP treated patients, lung function remained unchanged; mean $\mathrm{FEV}_{1}$ : 66.4 and $68.1 \%$ pred, respectively. This treatment effect was statistically significant $(p<0.05$, rmANOVA test), and considered as a beneficial effect of FP treatment. Parameters of BHR were not influenced by FP treatment.

\section{Immunocytology}

BAL fluid recovery was higher in controls as compared to the COPD patients (Table 2). Mean total cell number of the BAL at the start of the trial was $49 \times 10^{6}$ for FP treated patients and $44 \times 10^{6}$ in the placebo group (Table 2, no statistical significant difference). Small changes were noticed in the BAL cell numbers at the end of the trial, which were not significant (Table 2). The percentages of fluid recovery, cell viability and cells types were not statistically different between both patient groups at baseline, and did not change significantly after 6 months of intervention
(Table 2). The low number of eosinophils indicates that COPD was stable in nature. ${ }^{2}$

\section{Arachidonic Acid metabolites}

Table 3 shows the levels of protein, albumin and AA metabolites at the start and after six months of intervention, which consisted of either FP inhalation or placebo. The results of the initial measurements in the FP-treated patients and the placebo group are comparatively equal $(p>0.05$, Mann-Whitney test). There are also no significant differences when comparing the COPD patients with the controls. Statistically significant differences (comparing post- and pre-intervention results) were found in the FP-treated patients with regard to $\mathrm{PGE}_{2}, 6 \mathrm{kPGF}_{1} \alpha$ and $\mathrm{PGF}_{2} \alpha$ $(p<0.05$, Wilcoxon signed rank test). After correction for protein levels, the results from the statistical tests were similar and also significant for the same three mediators (data not shown). The change of levels of $6 \mathrm{kPGF}_{1} \alpha$ and $\mathrm{PGF}_{2} \alpha$ differed significantly from that in the placebo group [treatment effect] $(p<0.05$, Wilcoxon signed rank test).

\section{Discussion}

In a subgroup of COPD patients, particularly those with bronchial hyperresponsiveness, we were able to measure levels of cyclooxygenase and 5-lipoxygenase products in BAL fluid and observed sig-

Table 2. Characteristics of bronchoalveolar lavage

\begin{tabular}{|c|c|c|c|c|c|}
\hline & \multicolumn{2}{|c|}{ Fluticasone propionate } & \multicolumn{2}{|c|}{ Placebo } & \multirow{2}{*}{$\begin{array}{c}\text { Asymptomatic } \\
\text { smokers }\end{array}$} \\
\hline & Start & 6 months & Start & 6 months & \\
\hline Fluid recovery, \% & $55 \pm 14$ & $57 \pm 14$ & $55 \pm 15$ & $50 \pm 19$ & $69 \pm 2.2$ \\
\hline Cell number, $\times 10^{6}$ & $49 \pm 24$ & $47 \pm 31$ & $44 \pm 27$ & $40 \pm 23$ & $53 \pm 27$ \\
\hline Cell viability, \% & $62 \pm 12$ & $66 \pm 12$ & $70 \pm 13$ & $67 \pm 12$ & $66 \pm 14$ \\
\hline $\mathrm{CD} 8^{+}$macrophages, $\%$ & $93 \pm 8$ & $94 \pm 4$ & $94 \pm 4$ & $91 \pm 7$ & $93 \pm 7$ \\
\hline $\mathrm{CD}_{15}{ }^{+}$granulocytes, $\%$ & $2.9 \pm 2.5$ & $2.8 \pm 2.7$ & $2.8 \pm 2.7$ & $3.6 \pm 6.4$ & $1.7 \pm 1.6$ \\
\hline BMK $13^{+}$eosinophils, \% & $0.6 \pm 0.4$ & $0.5 \pm 0.4$ & $0.5 \pm 0.4$ & $1.0 \pm 1.3$ & $0.9 \pm 0.1$ \\
\hline $\mathrm{CD}^{+}$T-cells, $\%$ & $1.3 \pm 1.9$ & $0.7 \pm 0.6$ & $3.8 \pm 4.8$ & $5.9 \pm 5.2$ & $1.8 \pm 1.9$ \\
\hline
\end{tabular}

Mean $\pm S D$ 


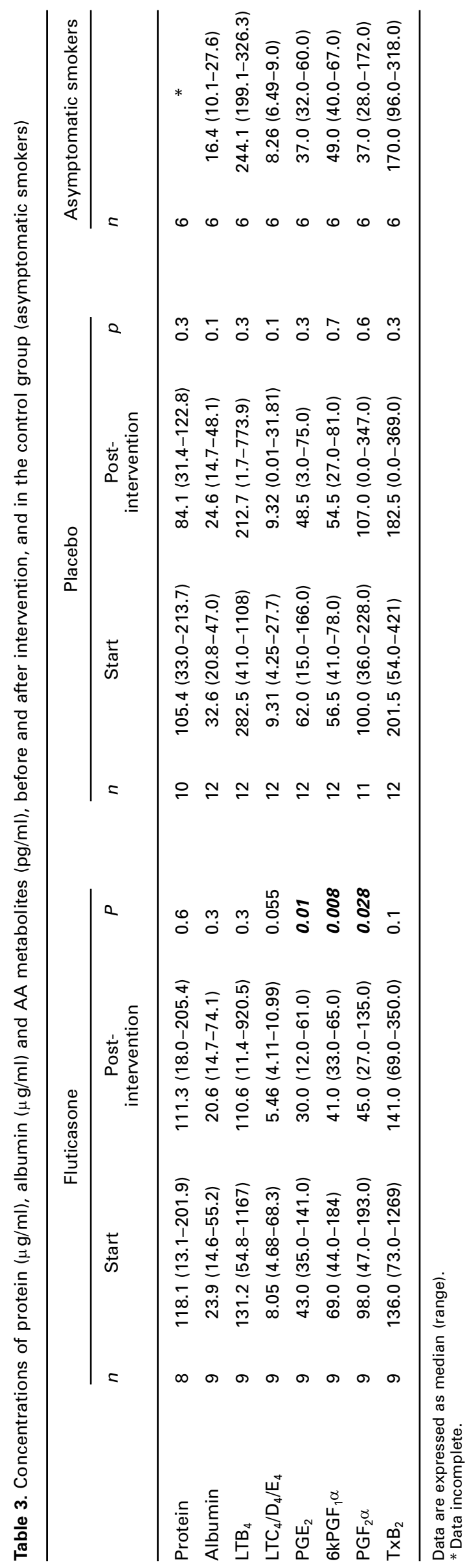


nificant decreases of three out of six mediators after inhaled fluticasone propionate therapy, in a placebo controlled trial that lasted for six months (Table 3). Arachidonic acid metabolites have gained attention in asthma, in which they play an important role as mediators of inflammation with bronchoconstriction as the most important clinical effect. In a previous study in our institution concerning asthma patients we have used the same techniques for collecting BAL fluid and measuring levels of AA metabolites. ${ }^{9}$ These patients had a similar degree of BHR (as expressed by $\mathrm{PC}_{20}$ ) compared to the COPD patients in the present study. However, these asthma patients had a history consistent with asthma, they had allergic reactions for common inhaled allergens and were non-smokers. $\mathrm{LTC}_{4} / \mathrm{D}_{4} / \mathrm{E}_{4}$ levels were comparable, whereas levels of $\mathrm{TxB}_{2}, \mathrm{PGE}_{2}$ and $6 \mathrm{kPGF}_{1} \alpha$ were, respectively, approximately 10-, 5- and 15-fold higher in COPD as compared to asthma. The number of cells in the BAL fluid was, however, about five times higher in COPD as compared to asthma. Taking this into account, it appears that cell secretory activity with regard to $\mathrm{LTC}_{4} / \mathrm{D}_{4} / \mathrm{E}_{4}$ is higher in asthma. This is feasible because asthma is an allergic inflammatory disease, whereas in COPD there is a non-specific inflammatory infiltrate. The production of $\mathrm{LTC}_{4} / \mathrm{D}_{4} / \mathrm{E}_{4}$ is almost exclusively attributed to mast cells, which are numerous in the airway walls of asthma patients, whereas they are hardly detectable in COPD. On the other hand, inflammatory cells in COPD seem to produce higher amounts of $\mathrm{TxB}_{2}$ and $6 \mathrm{kPGF}_{1} \alpha$. The most obvious explanation seems to be that this is induced by cigarette smoking. In one other study we have shown that levels of $\mathrm{TxB}_{2}$ and $\mathrm{PGF}_{2} \alpha$ in $\mathrm{BAL}$ fluid were significantly elevated in smokers as compared to non-smokers, and this correlated with packyears. ${ }^{8}$ Smoking also increased the pentagastrin-stimulated gastric luminal release of $\mathrm{TxB}_{2}$ and $\mathrm{PGF}_{2} \alpha{ }^{10}$ In the present study, we have compared levels of these mediators in smoking COPD patients with the levels in a control group which consisted of asymptomatic smokers with normal lung function and negative allergy tests. There were no significant differences. These results indicate that smoking (and not some mechanism specific for COPD) could be the single or most important stimulus for an inflammatory infiltrate with high levels of certain cyclooxygenase products. ${ }^{11}$

Fluticasone propionate (FP) had no significant effect on BAL cellularity or on protein and albumin levels (Table 2). Apparently, the influx and the survival of cells were not affected by this potent topical glucocorticoid. FP also did not influence the levels of the leukotrienes. However, cell secretory activity, particularly the production of $\mathrm{PGE}_{2}, 6 \mathrm{KPGF}_{1} \alpha$ and $\mathrm{PGF}_{2} \alpha$, was inhibited as their levels were decreased after 6 months exposure to FP (Table 3).
In the above mentioned previous study of asthma patients the same dose of FP was used. ${ }^{9}$ From the AA metabolites in asthma, only $\mathrm{PGD}_{2}$ decreased significantly. Levels of $\mathrm{PGF}_{2} \alpha$ were not measured in that study. One other study in asthma patients also showed lower levels of $\mathrm{PGD}_{2}$ in $\mathrm{BAL}$ fluid after inhaled glucocorticoid therapy. ${ }^{12}$ It was concluded that, in asthma, FP downregulated the capability of mast cells, and perhaps also of alveolar macrophages, to produce $\mathrm{PGD}_{2}$. From our present study in COPD patients we conclude that FP causes downregulation of the capability of alveolar macrophages to produce certain prostaglandins.

In the present study, the statistically significant clinical effect of FP treatment in COPD patients with BHR was not a reduction of any parameter related to BHR, but the course of the $\mathrm{FEV}_{1}$ : it decreased in the placebo group, whereas it remained stable in the FPtreated patients. So, in the placebo group the ongoing inflammation made airway obstruction worse. Antiinflammatory therapy with FP obliterated $\mathrm{FEV}_{1}$ decline, and one of the mechanisms underlying this effect could be the reduction of levels of AA metabolites, particularly $\mathrm{PGF}_{2} \alpha . \mathrm{PGF}_{2} \alpha$ has strong bronchoconstrictor activity through a direct effect on airway receptors and indirectly through cholinergic-mediated bronchoconstriction. ${ }^{13}$ Reduction of its level could diminish bronchomoter tone. We also observed a significant decrease in the levels of $6 \mathrm{kPGF}_{1} \alpha$ and $\mathrm{PGE}_{2} .6 \mathrm{kPGF}_{1} \alpha$ is derived from $\mathrm{PGI}_{2}$, which is, like $\mathrm{PGE}_{2}$, a mediator with, amongst others, a bronchodilatory effect. Apparently, the activity of these PGs in COPD is less as compared to the activity of $\mathrm{PGF}_{2} \alpha$. In murine lower airways $\mathrm{PGF}_{2} \alpha$ was the most potent bronchial muscle constrictor. ${ }^{14}$ Alternatively, other inflammatory mechanisms could be more important for explaining the clinical effect of FP which we observed in this particular group of COPD patients.

In conclusion, the ongoing inflammation with, amongst others, high concentrations of $\mathrm{PGF}_{2} \alpha$ made airway obstruction worse, whereas inhibition of $\mathrm{PGF}_{2} \alpha$ production by $\mathrm{FP}$ seems to be one of the mechanisms leading to preservation of lung function.

ACKNOWLEDGEMENTS. This study was financially supported by the Netherlands Asthma Foundation and by GlaxoWellcome, the Netherlands (FLIL44/FMS40060).

\section{References}

1. Saetta M. Airway inflammation in chronic obstructive pulmonary disease. Am J Respir Crit Care Med 1999: 160:S17-S20.

2. Jeffery PK. Comparison of the structural and inflammatory features of COPD and asthma. Gilles F. Filley Lecture. Chest 2000: 117(Suppl. 1):251S-60S

3. Rijcken B, Schouten JP, Xu X, Rosner B, Weiss ST. Airway hyperresponsiveness to histamine associated with accelerated decline in $\mathrm{FEV}_{1}$. Am J Respir Crit Care Med 1995: 151:1377-82.

4. Tashkin DP, Altose MD, Connett JE, Kanner RE, Lee WW, Wise RA. Methacholine reactivity predicts changes in lung function over time in smokers with early chronic obstructive pulmonary disease. The Lung Health Study Group. Am J Respir Crit Care Med 1996: 153:1802-11. 
5. ATS Statement. Standards for the diagnosis and care of patients with chronic obstructive pulmonary disease. Am J Respir Crit Care Med 1995: 152:S77-S120.

6. Quanjer PhH, Tammeling GJ, Cotes JE, Pedersen OF, Peslin R, Yernault JC. Lung volumes and forced ventilatory flows. Eur RespirJ 1993: 6(Suppl. 16):5-40

7. Summary and recommendations of a workshop on the investigative use of fiberoptic bronchoscopy and bronchoalveolar lavage in asthmatics. Am Rev Respir Dis 1985: 132:180-2.

8. Zijlstra FJ, Vincent JE, MolWM, Hoogsteden HC, Van Hal PT, Jongejan RC. Eicosanoid levels in bronchoalveolar lavage fluid of young female smokers and non-smokers. Eur J Clin Invest 1992: 22:301-6.

9. Overbeek SE, Bogaard JM, Garrelds IM, Zijlstra FJ, Mulder PGH Hoogsteden HC. Effects of fluticasone propionate on arachidonic acid metabolites in BAL-fluid and metacholine dose-response curves in nonsmoking atopic asthmatics. Mediators of Inflammation 1996 5:224-9.

10. Fedi P, Calabro A, Orsini B, Milani S, Zacchi P, Salvadori G, et al. Cigarette smoking increases gastric luminal prostaglandin $\mathrm{F}_{2}$ alpha and thromboxane $B_{2}$ in healthy smokers. Digestion 1990: 46:27-34.
11. Lee LY, Hong JL. Involvement of prostanoids in cigarette smokinginduced pathophysiological effects in the lung. Prostaglandins Leukot Essent Fatty Acids 1999: 61:145-55.

12. Oosterhoff Y, Overbeek SE, Douma R, Noordhoek JA, Postma DS, Hoogsteden HC, et al. Lower leukotriene C4 levels in bronchoalveolar lavage fluid after 2.5 years inhaled corticosteroid therapy. Mediators of Inflammation 1995: 4:426-30.

13. Beasly R, Varly J, Robinson C, Holgate ST. Cholinergic-mediated bronchoconstriction induced by prostaglandin $\mathrm{D}_{2}$, its initial metabolite $9_{\mathrm{ga}}, 11 \beta-\mathrm{PGF}_{2} \alpha$ and $\mathrm{PGF}_{2} \alpha$ in asthma. Am Rev Respir Dis 1987: 136:1140-4.

14. Richter M, Sirois P. Effects of eicosanoids, neuromediators and bioactive peptides on murine airways. Eur J Pharmacol 2000: 389:225-34

\section{Received 6 November 2000; accepted 5 January 2001}




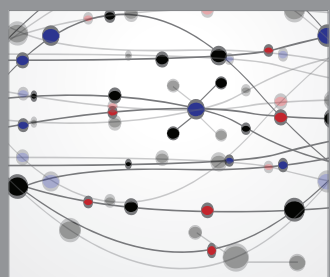

The Scientific World Journal
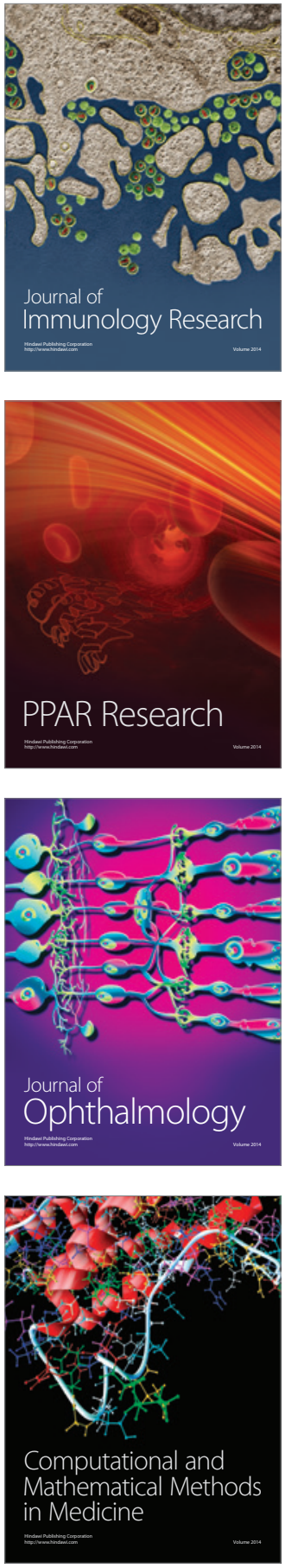

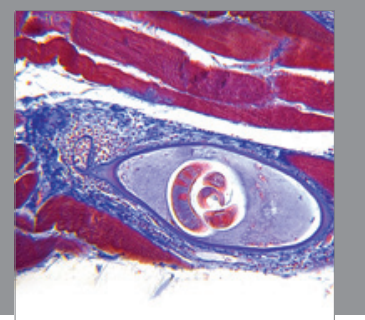

Gastroenterology

Research and Practice
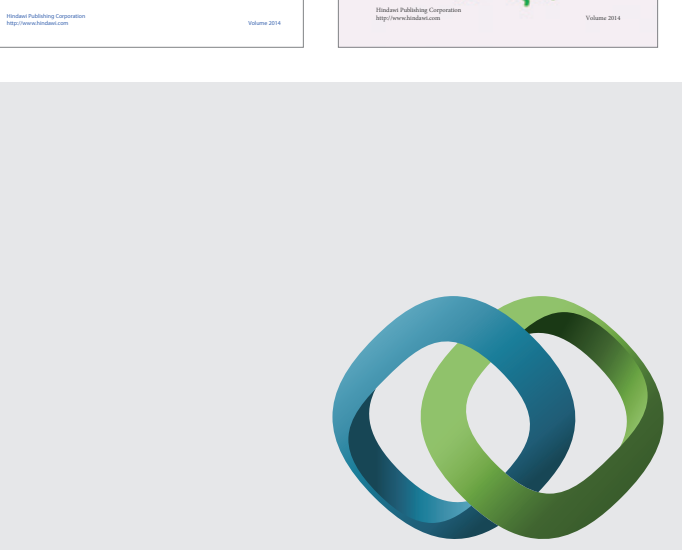

\section{Hindawi}

Submit your manuscripts at

http://www.hindawi.com
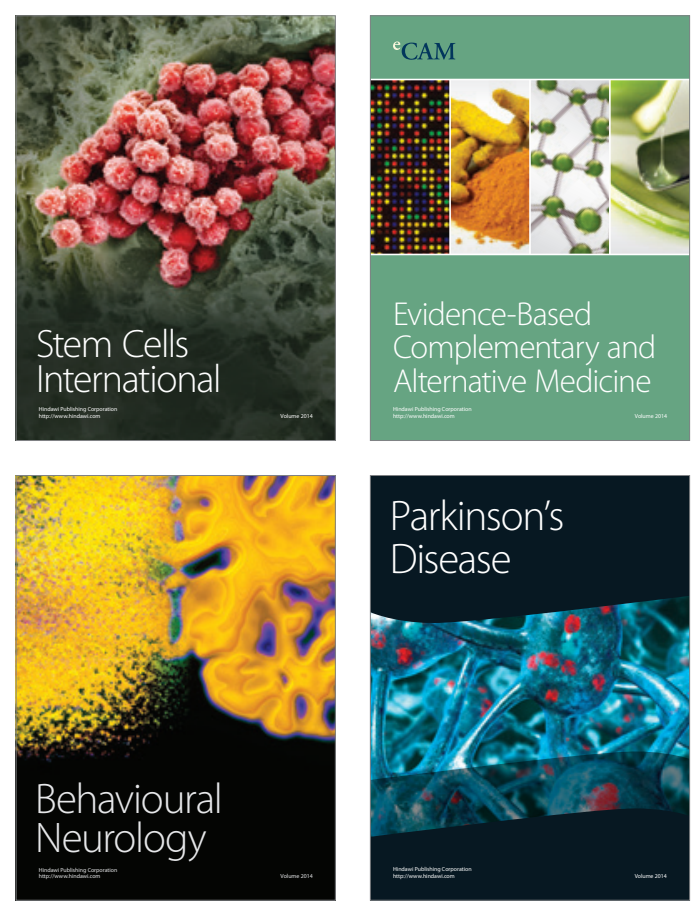

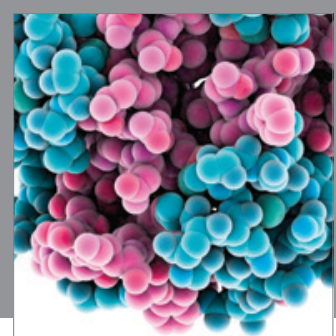

Journal of
Diabetes Research

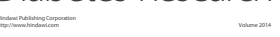

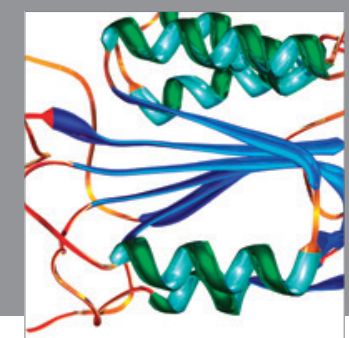

Disease Markers
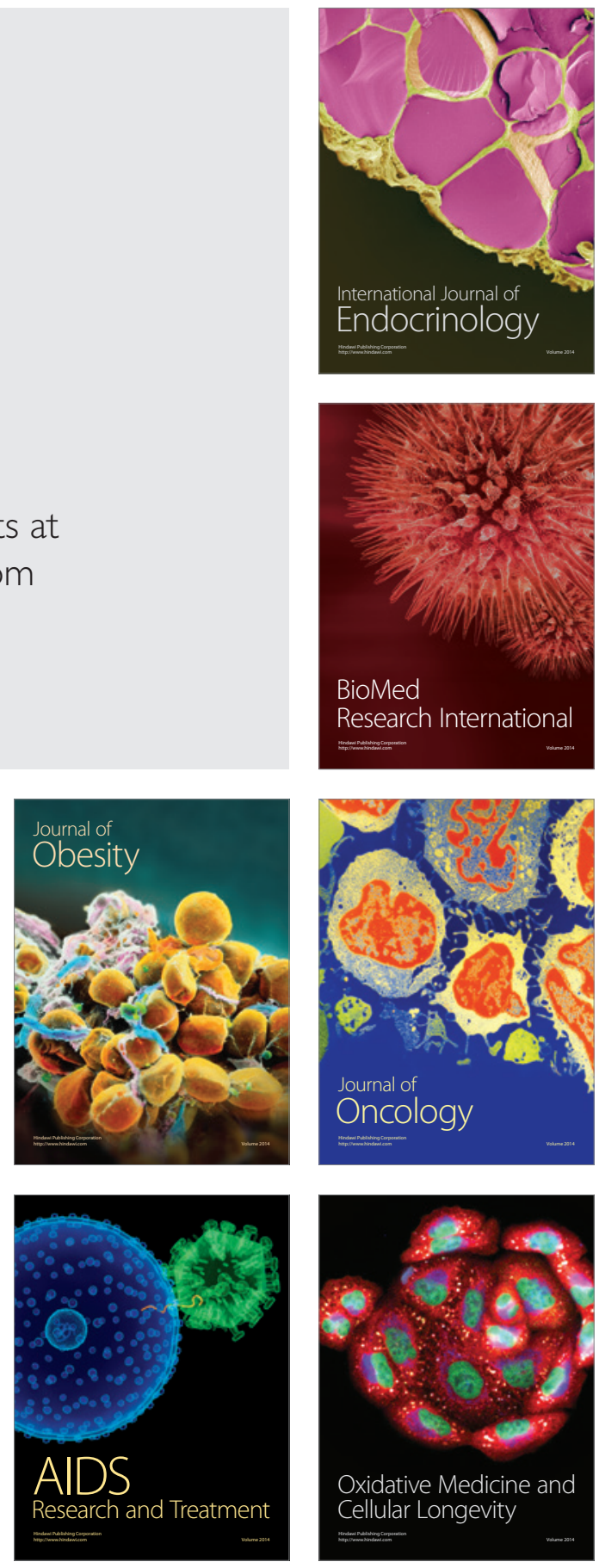